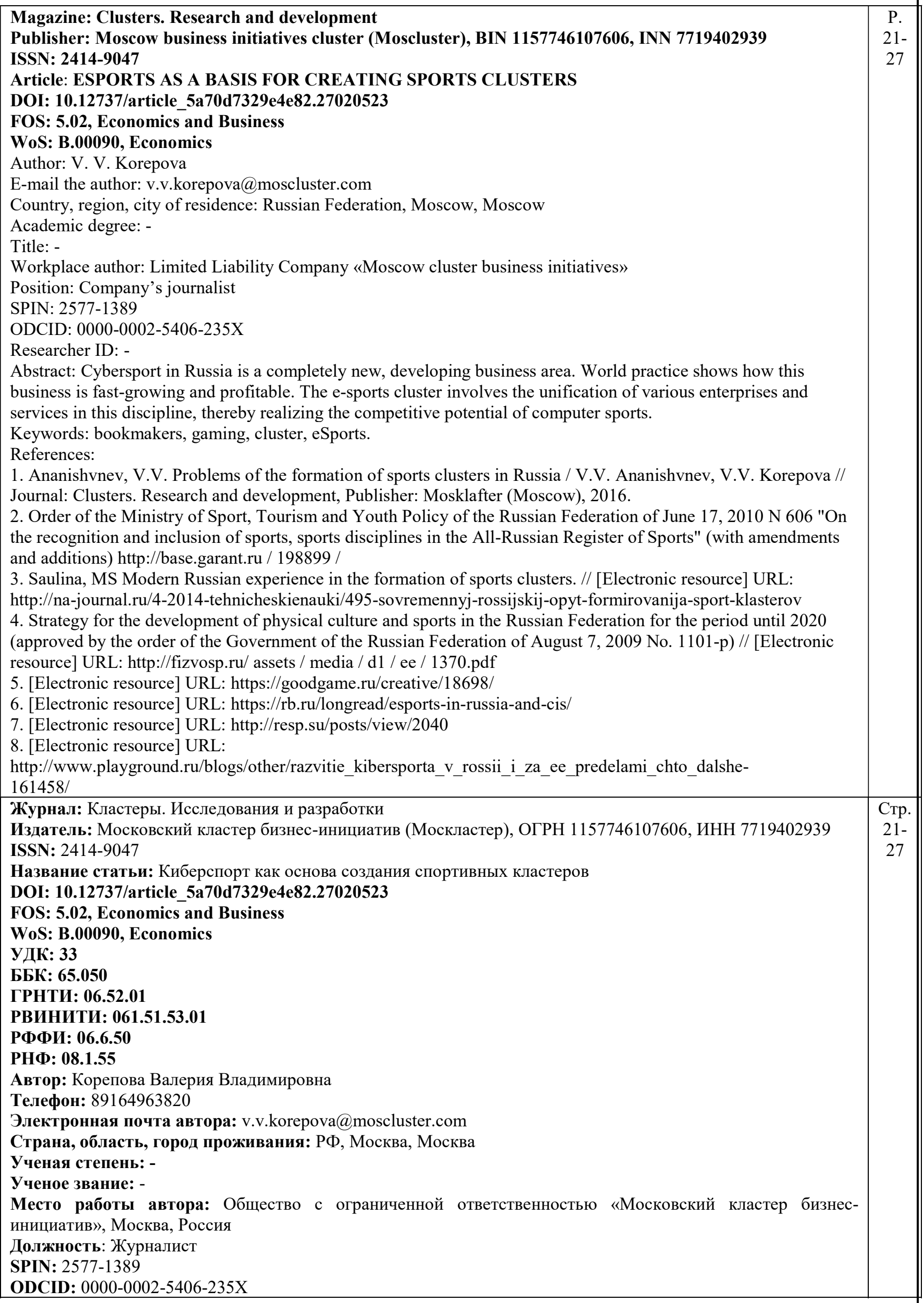




\begin{abstract}
Researcher ID:-
Аннотация: Киберспорт в России - совсем новая, развивающаяся сфера бизнеса. Мировые практики показывают насколько этот бизнес быстрорастущий и прибыльный. Киберспортивный кластер предполагает объединение различных предприятий и услуг по данной дисциплине, тем самым реализуя конкурентный потенциал компьютерного спорта.
\end{abstract}

Ключевые слова: букмекеры , игры, кластер, киберспорт.

\title{
Рецензия 1:
}

Фамилия Имя Отчество рецензента, место работы и должность, ученая степень, присвоенная или нострифицированная ВАК Минобрнауки России, зарегистрированного на сайте elibrary.ru: Тарасенко Владислав Валерьевич, МГУТУ им. К.Г. Разумовского, кандидат философских наук.

Степень актуальности предоставляемой статьи (соответствие содержания статьи заявленной в названии теме, соответствие современным достижениям науки, доступность читателям с точки зрения языка, стиля, расположения материала, наглядности таблиц, диаграмм, рисунков и формул): В статье поднимается проблема киберспортивных состязаний, связанная с невозможностью деления на спортивные дисциплины. Это обусловлено владением конкретной игры определённой компанией и в случае прекращения функционирования компании соревнования, основанные на данной игре, придётся прекратить. Тем самым автор подводит к тому, что киберспорту необходимо создание кластера. Актуальностью идеи является определение автором ниши киберспортивных состязаний и определения участников киберспортивного кластера. Автор приводя определённые примеры, производит анализ сегмента рынка и выявляет способы его контроля.

Рекомендацию к публикации (в чем конкретно заключаются положительные стороны, а также недостатки статьи, какие исправления и дополнения должны быть внесены автором, целесообразность публикации статьи с учетом ранее вышедших в свет публикаций): Автор предлагает инновационный подход $\mathrm{\kappa}$ реализации киберспорта. Положительной стороной статьи является своевременность и актуальность данной темы. При это Россия ещё не в полной мере познала прибыльность данного бизнеса, в отличии от таких стран как Южная Корея и другие. Рекомендую статью к публикации в Фирменном научно-практическом журнале Московского кластера бизнес-инициатив (Москластер) «Кластеры. Исследования и разработки». Полагаю, что рецензируемая статья заслуживает публикации в научном издании, включенном в Перечень ВАК и РИНЦ (elibrary.ru).

Рецензия 2:

Фамилия Имя Отчество рецензента, место работы и должность, ученая степень, присвоенная или нострифицированная ВАК Минобрнауки России, зарегистрированного на сайте elibrary.ru: Ананишнев Владислав Владимирович, ООО «Москластер», Кандидат экономических наук.

Степень актуальности предоставляемой статьи (соответствие содержания статьи заявленной в названии теме, соответствие современным достижениям науки, доступность читателям с точки зрения языка, стиля, расположения материала, наглядности таблиц, диаграмм, рисунков и формул): Статья освещает проблему по реализации дисциплины "киберспорт" Министерством спорта, туризма и молодежной политики, поскольку дисциплина компьютерных игр представляет из себя одну игру, игры считаются собственностью компаний, дисциплина будет напрямую зависеть от компании, при ликвидации которой, дисциплину придется закрыть. Поэтому данной дисциплине нужен иной подход, а именно создание киберспортивного кластера. Актуальность идей, содержащихся в рецензируемой рукописи заключается в формулировке участников киберспортивного кластера и определения ниш в киберспорте. Автор в своей работе осуществил подробный анализ текущего состояния рынка киберспорта и выявил способы монетизации.

Рекомендацию к публикации (в чем конкретно заключаются положительные стороны, а также недостатки статьи, какие исправления и дополнения должны быть внесены автором, целесообразность публикации статьи с учетом ранее вышедших в свет публикаций): Автор предлагает интересный подход по реализации киберспорта в России. Положительная сторона статьи заключается в новизне, поскольку киберспорт в России совсем новая, развивающаяся сфера бизнеса. Мировые практики показывают насколько он быстрорастущий и прибыльный. Рекомендую статью к публикации в Фирменном научно-практическом журнале Московского кластера бизнес-инициатив (Москластер) «Кластеры. Исследования и разработки». Полагаю, что рецензируемая статья заслуживает публикации в научном издании, включенном в Перечень ВАК и РИНЦ (elibrary.ru).

\section{Одной из приоритетных задач развития физической культуры и спорта в} России, указанных в стратегии развитии физической культуры и спорта в Российской Федерации на период до 2020 года, является развитие спортивной индустрии. Данное развитие имеет большую значимость для социально- 
экономического развития региона и повышения конкурентоспособности спорта государства [1].

Приказом Министерства спорта, туризма и молодежной политики от 17.06.2010 №606 «О признании и включении видов спорта, спортивных дисциплин во Всероссийский реестр видов спорта» в список официальных видов спорта вносится новый - «компьютерный спорт», соревнования по которой могут проходить под эгидой Министерства спорта, а по итогам этих соревнований и после выполнения установленных квалификационных нормативов, самым успешным киберспортсменам могут присуждаться звания «Мастер спорта России», «Мастер спорта международного класса» и «Заслуженный мастер спорта России». $[2]$.

Компьютерный спорт (далее «киберспорт») - игровые соревнования, где компьютер моделирует виртуальное пространство, внутри которого происходит состязание и объекты, которыми управляет спортсмен [7].

Индустрия киберспорта зародилась еще в конце 90-х годов в США. Все началось с появления игры Doom 2, в которую можно было играть по локальной сети. Первая киберспортивная организация, занимавшаяся проведением турниров, появилась в 1997 году в США. Она называлась The Cyberathlete Professional League. Организация проводила ежегодные турниры сначала по игре Quake, а позднее и по другим популярным играм.

В 2001 году был анонсирован масштабный турнир в Азии под названием World Cyber Games (WCG). Соревнования проводились благодаря инвестициям одной из популярнейших в мире компаний, специализирующихся на производстве цифровой техники - Samsung Electronics. Турнир проходил каждый год, собирая множество сильнейших игроков со всего света. В 2006 году, компания Microsoft также стала партнером WCG.

С 2003 года, на просторах СНГ начал проводиться первый для нашего региона крупный киберспортивный турнир - Asus Open. На нем были представлены все самые популярные на тот момент компьютерные игры (в киберспорте их принято называть “киберспортивными дисциплинами”). Этот чемпионат проводился на протяжении 10 лет и послужил серьезным толчком для развития индустрии в СНГ. Партнерами турнира стали известные во всем мире компании Intel и Microsoft [8].

Ранее «киберспорт» уже входил в реестр Всероссийских видов спорта, но был исключен из Реестра приказом руководителя Росспорта Вячеслава Фетисова в июле 2006 года. Возвращение официального статуса киберспорта в 2016 году стало сигналом для участников рынка и инвестеров [4].

Оборот киберспортивного рынка в 2015 году составил 747.5 млн. долларов. Основная доля денежного оборота приходится на спонсорство и рекламу, поскольку за мировыми трансляциями игровых дисциплин следят миллионы зрителей. Поэтому крупнейшие компании борются за рекламные месте на крупных премиум-ивентах.

Bce это привлекает дополнительные инвестиции. Финансирование киберспортивных стартапов в 2015 году достигло 150 млн. долларов [5]. 
Пока что ни одна из конкретных киберспортивных дисциплин не признана, тем не менее, Министерство спорта выделило виды игровых дисциплин:

-трёхмерные шутеры (3D shooter), симуляция ведения боя между группами (командами) игроков.

- тактико-стратегическая игра - в игре происходят сражения между армиями игровых единиц игроков при одновременном развитии сторон.

- командные ролевые игры с элементами тактико-стратегической игры. Игрок управляет своей единичной моделью, развивая её при взаимодействии с игровым пространством и моделями других игроков.

- технические симуляторы - автомобильные и авиационные.

- симуляторы спортивных игр (футбол, хоккей, баскетбол) [7].

Что же представляет из себя дисциплина в компьютерных играх? Дисциплина в киберспорте - это одна игра, игры считаются собственностью компаний, поскольку существует закон об авторском праве, дисциплина будет напрямую зависеть от компании, при банкроте которой, дисциплину придется закрыть. Поэтому киберспорту нужен новый подход, а именно создание киберспортивного кластера.

Создание спортивного кластера предполагает объединение различных предприятий и услуг в сфере спорта, включающее тренировочный процесс, спортивные и культурно - зрелищные мероприятия разных уровней, реализующих конкурентный потенциал российского спорта [3].

\section{Участники киберспортивного кластера:}

1. Государственный орган, который реализует программу по развитию кластера.

2. Киберспортивные организации - поставщики успешных киберспортсменов, которые могут конкурировать на мировом уровне.

3. Финансовые институты - венчурные компании, частные инвестиционные фонды.

4. Медиа, СМИ - Телеканалы, стриминговые платформы, осуществляющие трансляции турниров.

5. Университеты, играющие роль по распространению киберспортивной дисциплины, путем организации турниров, введения факультативных дисциплин.

6. Организации по сотрудничеству - организаторы турниров, букмекеры.

7. Компании, производители игр.

В таблице 1 указаны наиболее развивающиеся и популярные киберспортивные дисциплины на сегодняшний день.

На данный момент российский киберспорт заметен на мировой арене. Наши игроки и команды находятся в топе вместе с представителями Китая и США. Они побеждают на турнирах и занимают призовые места.

Что касается дисциплин, то наиболее популярны в нашем регионе это: CS:GO, DOTA 2, World of Tanks, HearthStone. Именно эти киберспортивные игры пользуются наибольшим успехом у отечественных игроков. Стоит добавить, что первые две дисциплины имеют особую популярность. 
Самые популярные киберспортивные игры

\begin{tabular}{|c|c|c|c|}
\hline \multicolumn{4}{|c|}{ Топ -5 кибердисциплин с крупнейшим призовым фондом } \\
\hline Игра (издатель) & $\begin{array}{c}\text { Суммарный } \\
\text { призовой } \\
\text { фонд }\end{array}$ & $\begin{array}{l}\text { Количество } \\
\text { игроков }\end{array}$ & $\begin{array}{c}\text { Проведено } \\
\text { турниров }\end{array}$ \\
\hline Dote 2 (Valve) & $\$ 87,4$ млн & 1673 & 640 \\
\hline $\begin{array}{c}\text { League of Legends (Riot } \\
\text { Games) }\end{array}$ & $\$ 30,9$ мЛн & 4258 & 1754 \\
\hline Counter-Strike (VaIve) & $\$ 33$ млн & 8560 & 2458 \\
\hline StarCraft (Blizzard) & $\$ 27,4$ мЛн & 2118 & 4265 \\
\hline Smite (Hi-Rez Studios) & $\$ 5,8$ млн & 425 & 71 \\
\hline \multicolumn{4}{|c|}{ Другие претенденты в топ } \\
\hline Heroes of the Storm (Blizzard) & $\$ 5,7 \mathrm{мЛН}$ & 776 & 341 \\
\hline Hearthstone (Blizzard) & $\$ 5,4$ млн & 1017 & 502 \\
\hline World of Tanks (Wargaming) & $\$ 2,9$ млн & 340 & 44 \\
\hline WarCraft III (Blizzard) & $\$ 4,4$ мЛн & 385 & 815 \\
\hline World of WarCraft (Blizzard) & $\$ 2,6 \mathrm{млн}$ & 251 & 67 \\
\hline Overwatch (Blizzard) & $\$ 1,1$ млн & 660 & 157 \\
\hline FIFA (Electronic Arts) & $\$ 0,78$ млн & 597 & 679 \\
\hline
\end{tabular}

Таблица 2

Российский рынок киберспорта

\begin{tabular}{|c|c|c|}
\hline & 2016 год & 2018 год \\
\hline Объем рынка & $\$ 35,4 \mathrm{MлH}$ & $\$ 43,7 \mathrm{MлH}$ \\
\hline Аудитория & $\begin{array}{c}\$ 2,3 \mathrm{MлH} \\
\text { человек }\end{array}$ & $\begin{array}{c}\$ 4,3 \mathrm{M} л \mathrm{H} \\
\text { человек }\end{array}$ \\
\hline
\end{tabular}

Исходя из исследования аналитики SuperData и PayPal, Россия - лидер европейского региона как по объему рынка $(\$ 35,4$ млн), так и по аудитории киберспорта (2,2 млн).

\section{Основные ниши киберспорта:}

1. Создатели игр (приток новых геймеров в игру и развитие внутриигровой экономики)

2. Организаторы турниров (продажа билетов и прав на трансляцию, контракты со спонсорами)

3. Стриминговые платформы и телеканалы (реклама во время трансляций кибертурниров) 
4. Киберспортивные команды (спонсорство брендов, призы за победы в турнирах, продажа мерча фанатам)

5. Киберспортсмены (зарплата от команды, доля от призовых)

6. Букмекеры (доход от ставок на киберспорт) [6].

На сегодняшний день в России существует целый ряд крупных киберспортивных организаций, которые могут похвастаться несколькими составами по самым популярным дисциплинам в СНГ. Речь идет о Empire, Hellraisers, Vega Squadron, Moscow Five, и Virtus.pro, обладающие высоким бюджетом [8]. В таблице 3 указаны способы монетизации для разработчиков игр и для киберспортивных команд.

Таблица 3

\section{Стандартные способы монетизации}

\begin{tabular}{|c|c|}
\hline Для разработчиков игр & Для киберспортивной организации \\
\hline Создание внутриигрового магазина & \% от денежного приза команды \\
\hline Продажа мерча & Поддержка инвесторов \\
\hline Продажа игровой атрибутики & Продажа брендовой атрибутики \\
\hline Продажа клиента игры & Рекламные контракты с различными \\
& компаниями \\
\hline Продажа DLC (дополнений к играм) & $\begin{array}{c}\text { Доходы от просмотров на сайте уоutube и } \\
\text { на стриминговых каналах }\end{array}$ \\
\hline Создание и сотрудничество с & Доход от продажи мерча \\
интернет-площадками для ставок & \\
\hline
\end{tabular}

Основные источники денег в киберспорте являются крупные бренды. Они организуют большинство турниров и содержат киберспортивные команды. Это помогает им продвигать свои продукты среди обычных геймеров и удерживать многомиллионную аудиторию без ежемесячного выпуска новых фич. Самые денежные кибердисциплины - Dota 2, League of Legends и Counter-Strike.

Региональные отборочные этапы турниров проводятся онлайн. А вот финалы международных турниров требуют очного участия игроков (их называют LANфиналами). Команды из разных полушарий не могут профессионально сражаться в онлайне - даже минимальная задержка в сигнале отразится на игре.

Главный мировой турнир по Dota 2 - The International - проводит ee издатель Valve. За шесть лет призовой фонд турнира вырос с \$1,6 млн в 2011 году до \$24,7 млн в 2017 году. Характерно, что всю часть данных средств вносят простые геймеры, покупая внутриигровые предметы в Dota 2.

Американская Riot Games c 2011 года проводит крупнейший мировой чемпионат по своему главному продукту — League of Legends. За это время его призовой фонд вырос со \$100 тысяч до \$5 млн (2016 год). Теперь, когда кибертурниры собирают стадионы, многие издатели пытаются разрабатывать игры с прицелом на киберспорт.

Главным кибердисциплинам свойственны популярность и зрелищность, отмечает руководитель киберспортивного отдела компании Wargaming Алексей 
Корнышев. «Успех игры как дисциплины состоит из качества самого продукта и качества организации турниров. Футбол стал самым популярным видом спорта именно благодаря известным лигам».

Независимые организаторы кибертурниров зарабатывают на спонсорской поддержке, продаже билетов и трансляции мероприятий. Они продают рекламодателям внимание привлеченной аудитории. Кроме издателей игр, турниры чаще всего спонсируют производители компьютеров, электроники и геймерских девайсов, а также телеком [6].

Таким образом, киберспорт в России - совсем новая, развивающаяся сфера бизнеса. Мировые практики показывают насколько этот бизнес быстрорастущий и прибыльный. Киберспортивный кластер предполагает сближение участников кластера, с целью достижения профессионального уровня в киберспортивной дисциплине, а также насыщения спортивной индустрии дополнительными развлекательными функциями.

\section{Список литературы}

1. Ананишнев, В.В. Проблемы формирования спортивных кластеров в России / В.В. Ананишнев, В.В. Корепова // Журнал: Кластеры. Исследования и разработки, Издательство: Москластер (Москва), 2016.

2. Приказ Министерства спорта, туризма и молодёжной политики РФ от 17 июня 2010 г. N 606 "О признании и включении видов спорта, спортивных дисциплин во Всероссийский реестр видов спорта" (с изменениями и дополнениями) http://base.garant.ru/198899/

3. Саулина, М. С. Современный российский опыт формирования спорткластеров. // [Электронный pecypc] URL: http://na-journal.ru/4-2014tehnicheskienauki/495-sovremennyj-rossijskij-opyt-formirovanija-sport-klasterov

4. Стратегия развития физической культуры и спорта в Российской Федерации на период до 2020 года (утв. распоряжением Правительства Российской Федерации от 7 августа 2009 г. № 1101-p) // [Электронный ресурс] URL: http://fizvosp.ru/assets/media/d1/ee/1370.pdf

5. [Электронный ресурс] URL: https://goodgame.ru/creative/18698/

6. [Электронный ресурc] URL: https://rb.ru/longread/esports-in-russia-and-cis/

7. [Электронный ресурc] URL: http://resp.su/posts/view/2040

8.[Электронныйресурс]URL:http://www.playground.ru/blogs/other/razvitie_kiber sporta_v_rossii_i_za_ee_predelami_chto_dalshe-161458/ 